\title{
Should we measure dyspnoea in everyone?
}

\author{
Robert B. Banzett ${ }^{1,2}$ and Carl R. O'Donnell ${ }^{1,2}$ \\ Affiliations: 'Dept of Medicine, Harvard Medical School, Boston, MA, USA. ${ }^{2}$ Division of Pulmonary, Critical Care, \\ and Sleep Medicine, Beth Israel Deaconess Medical Center, Boston, MA, USA.
}

Correspondence: Robert B. Banzett, Division of Pulmonary, Critical Care, and Sleep Medicine, Beth Israel Deaconess Medical Center, 330 Brookline Ave, Boston, MA 02215, USA. E-mail: rbanzettabidmc.harvard.edu

$\boldsymbol{0}$ @ERSpublications

Dyspnoea is easy to measure, prevalent and predicts mortality/morbidity risk; we urge assessment for all patients http://ow.ly/vE9Hh

Dyspnoea is defined as "breathing discomfort" [1]. The paper by GrøNSETH et al. [2] in this issue of European Respiratory Journal (ERJ) reports the prevalence of dyspnoea in 15 countries throughout the world. There are few studies of dyspnoea in the general population available, so this added information is welcome. The overall prevalence of dyspnoea in their study population was $27 \%$, which is not far out of line with several other studies dating from 1964 to the present [3-5]. Some studies, based on review of medical records, have reported much lower prevalence [6]. However, patients may neglect to report dyspnoea to their clinician because they think it does not reach a sufficient level of importance, or clinicians may fail to record what their patients say. Requiring patients to scale their symptoms can result in more uniform reporting, because the patient does not have to decide how much is reportable, it takes very little time and it facilitates uniform documentation. Busy clinicians may ask "is dyspnoea worth documenting?" One powerful argument for routine assessment is the need to reduce suffering, as with pain. A second argument is the emerging predictive value of dyspnoea in forecasting medical needs.

In addition to being prevalent, "dyspnoea" is a powerfully aversive sensation [7] and patients deserve adequate management of this symptom, as passionately argued by CuRROw et al. [8]. Effective interventions exist and should be used [9-11]; assessing dyspnoea is the first step in managing it. Dyspnoea is frequently overlooked despite its prevalence and the severity of distress it causes [12]. For example, despite having had dyspnoea for months a majority of advanced cancer patients had not received any treatment for it [13]. Historically, funding for dyspnoea research is a small fraction of the funding for pain research, and the field is, not surprisingly, behind [14]. Yet in recent years, real progress has been made in understanding dyspnoea, for examples see the report of a recent experts meeting in this issue of the ERJ [15]. A great deal remains to be learned, but we now have a much better understanding of the neurophysiology underlying dyspnoea, including several studies of brain activity [16].

Dyspnoea is often dismissed as merely "subjective" in contrast to the increasingly relied upon high-tech measurements that are assumed to yield more valuable "objective" data. We know there is a wide variation among patients in the degree of discomfort reported for apparently similar objective pathophysiological impairment. Although large studies have shown a statistically significant relationship between dyspnoea and airway obstruction (forced expiratory volume in $1 \mathrm{~s}(\mathrm{FEV} 1)$ ), a scatter plot of the data reveals a huge variance among patients; there are many patients with severe airways obstruction who report no dyspnoea and many others who report severe dyspnoea without correspondingly severe pathophysiology [17]. Indeed, GRøNSETH et al. [2] found that a model incorporating about 20 demographic and clinical variables,

Received: Feb 162014 | Accepted after revision: April 072014

Support statement: This work was supported by NIH grants NR10006 and NR12009.

Conflict of interest: Disclosures can be found alongside the online version of this article at www.erj.ersjournals.com

Copyright @ERS 2014 
including lung function measurements, explained only $13 \%$ of the individual variation in dyspnoea. Other studies have reported weak correlation of dyspnoea with objective measures such as FEV1 in chronic obstructive pulmonary disease (COPD) [18] and haemodynamic measures in heart failure [19]. Some of the variation in the dyspnoea-pathophysiology relationship reflects differences in how individuals experience discomfort and some reflects differences in how individuals choose to report the discomfort they experience. However, one must also consider the possibility that an important part of the variation in the relationship between dyspnoea and pathophysiology reflects the inability of our "objective" measures to accurately assess the most important features of pathophysiology. The body has been equipped by evolution with thousands of enteroceptors to detect problems in the crucial systems that support the gas exchange essential to life. When these enteroceptors detect malfunctioning gas transport systems, the message reaches consciousness as dyspnoea. Perhaps, despite the degradation of information in the pathway from enteroceptors through conscious perception to patient report, the information from enteroceptors is so rich that even the degraded information is as valuable as the relatively sparse information available from "objective" clinical tests.

Some interesting outcome studies suggest that patient-reported dyspnoea is indeed valuable information. In COPD patients, dyspnoea severity was a much stronger predictor of 5-year mortality than FEV1 (fig. 1) [20]; dyspnoea predicted cardiac death better than angina in patients with suspected cardiac disease [21]; dyspnoea was a stronger predictor of mortality than gastrointestinal symptoms in oesophageal and gastric cancer patients [22, 23]; and dyspnoea was a strong predictor of all-cause mortality in more general populations [5, 24, 25]. A growing body of evidence suggests that routine measurement and documentation of dyspnoea would have a clinical value disproportionate to the minimal effort needed to obtain the data. Our group has shown that routine nursing measurement of dyspnoea in hospitalised patients is feasible, and that it may provide useful risk prediction [26-28].

What is the best way to measure dyspnoea? The only clear answer is that using some form of quantitative scale is more useful than the yes/no approach. GRøNSETH et al. [2] utilised a form of the ubiquitous Medical Research Council (MRC) breathlessness scale ("Breathlessness" is most commonly used in this context in British English; "Shortness of Breath" is more common in the USA; and the word "Dyspn(o)ea" is not understood by most patients). The MRC scale was devised more than half a century ago to assess lung disease in coalminers, but has been widely used in many contexts [29]. The MRC scale assesses dyspnoea by asking which activities, ranging from vigorous exercise to minimal activities of daily living, are limited by dyspnoea. The MRC scale has shown good utility in many studies. A major drawback of the MRC scale in some populations is the lack of a scale point for patients who experience dyspnoea at rest, but it is easy to extend the scale to ask about dyspnoea at rest. Several lengthier scales are also available [30, 31]. However, scales such as the MRC are indirect; they do not actually ask the patient how much dyspnoea they experience. There are various scales used to assess dyspnoea directly, including single-dimension scales of respiratory discomfort, and multidimensional scales that assess discomfort, modality of sensation and emotional response [32-34]. The instrument used should suit the situation, for instance brevity may be
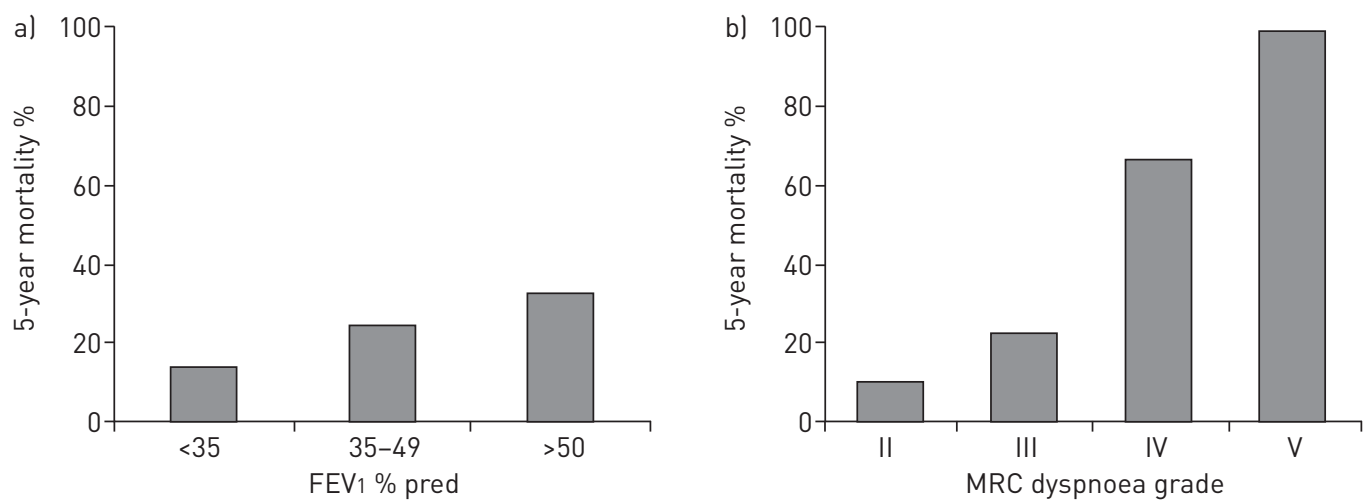

FIGURE 1 a) 5-year mortality rates of patients classified by pulmonary function test according to the American Thoracic Society guidelines. Stage I: forced expiratory volume in 1 s (FEV1) $>50 \%$ predicted; Stage II: FEV1 35-49\% pred; Stage III: FEV $1<35 \%$ pred. b) 5 -year mortality of patients classified by dyspnoea grade as measured using the Medical Research Council (MRC) breathlessness scale. Grade II: short of breath when hurrying on the level or walking up a slight hill; Grade III: have to walk slower than most people on the level; Grade IV: have to stop for breath after walking about 100 yards (or after a few minutes) on the level; Grade V: too breathless to leave the house, or breathless after undressing. Data from [20]. 
more important than completeness for routine clinical use, and different scales may be appropriate for outpatients versus inpatients. But even a simple measurement is better than no measurement.

GRøNSETH et al. [2] have used mutually standardised measures to extend the observation of dyspnoea prevalence and variance across several cultures and language groups. Their study found important differences in dyspnoea reports among the 15 countries sampled and between males and females across countries. We don't know if these differences really reflect variation in pathophysiology, which might be measured by hard outcomes such as morbidity and mortality, or whether they reflect differences in reporting rooted in sex, culture, language, etc. Such questions can be addressed, both in reductionist studies using highly controlled laboratory models of dyspnoea and in prospective population studies looking at hard outcomes.

Although dyspnoea measures have been shown to be useful predictors at a population level (potentially enabling better management of healthcare resources), better understanding of the variation in reporting among individuals and among groups of individuals is needed to refine the use of dyspnoea assessment at the individual prognostic level. Routine measurement in primary care and during hospitalisation may help overcome uncertainty introduced by interindividual variation, an individual's dyspnoea history is, therefore, likely to be more helpful than a snapshot in time. Despite the many unanswered questions about dyspnoea, we already know that simple measures in individual patients can be useful in tracking disease progress or treatment efficacy, can usefully supplement objective measures in diagnosis and prognosis, and are essential in targeting individual symptom management.

\section{References}

1 Parshall MB, Schwartzstein RM, Adams L, et al. An official American Thoracic Society statement: update on the mechanisms, assessment, and management of dyspnea. Am J Respir Crit Care Med 2012; 185: 435-452.

2 Grønseth R, Vollmer WM, Hardie JA, et al. Predictors of dyspnoea prevalence: results from the BOLD study. Eur Respir J 2014; 43: 1610-1620.

3 Hammond E. Some preliminary findings on physical complaints from a prospective study of 1,064,004 men and women. Am J Public Health 1964; 54: 11-23.

4 Kroenke K, Arrington ME, Mangelsdorff AD. The prevalence of symptoms in medical outpatients and the adequacy of therapy. Arch Intern Med 1990; 150: 1685-1689.

5 Frostad A, Søyseth V, Andersen A, et al. Respiratory symptoms as predictors of all-cause mortality in an urban community: a 30-year follow-up. J Intern Med 2006; 259: 520-529.

6 Kroenke K, Mangelsdorff AD. Common symptoms in ambulatory care: incidence, evaluation, therapy, and outcome. Am J Med 1989; 86: 262-266.

7 O’Driscoll M, Corner J, Bailey C. The experience of breathlessness in lung cancer. Eur J Cancer Care (Engl) 1999; 8: $37-43$.

8 Currow DC, Abernethy AP, Ko DN. The active identification and management of chronic refractory breathlessness is a human right. Thorax 2014; 69: 393-394.

9 Currow D, Johnson M, White P, et al. Evidence-based intervention for chronic refractory breathlessness: practical therapies that make a difference. Br J Gen Pract 2013; 63: 609-610.

10 Bausewein C, Booth S, Gysels M, et al. Non-pharmacological interventions for breathlessness in advanced stages of malignant and non-malignant diseases. Cochrane Database Syst Rev 2008; 2: CD005623.

11 Booth S, Farquhar M, Gysels M, et al. The impact of a breathlessness intervention service (BIS) on the lives of patients with intractable dyspnea: a qualitative phase 1 study. Palliat Support Care 2006; 4: 287-293.

12 Gysels M, Higginson IJ. Access to services for patients with chronic obstructive pulmonary disease: the invisibility of breathlessness. J Pain Symptom Manage 2008; 36: 451-460.

13 Roberts DK, Thorne SE, Pearson C. The experience of dyspnea in late-stage cancer. Patients' and nurses' perspectives. Cancer Nurs 1993; 16: 310-320.

14 Max MB. How to move pain and symptom research from the margin to the mainstream. J Pain 2003; 4: 355-360.

15 Laviolette L, Laveneziana P. Dyspnoea: a multidimensional and multidisciplinary approach. Eur Respir J 2014; 43: $1750-1762$.

16 Evans KE, Banzett RB. Neuroimaging of dyspnea. In: Mahler DA, O’Donnell DE, eds. Dyspnea: Mechanisms, Measurement, and Management. 3rd Edn. Boca Raton, CRC Press, 2014.

17 Müllerová $\mathrm{H}, \mathrm{Lu} \mathrm{C}, \mathrm{Li} \mathrm{H}$, et al. Prevalence and burden of breathlessness in patients with chronic obstructive pulmonary disease managed in primary care. PLoS One 2014; 9: e85540.

18 Bestall JC, Paul EA, Garrod R, et al. Usefulness of the Medical Research Council (MRC) dyspnoea scale as a measure of disability in patients with chronic obstructive pulmonary disease. Thorax 1999; 54: 581-586.

19 Guglin M, Patel T, Darbinyan N. Symptoms in heart failure correlate poorly with objective haemodynamic parameters. Int J Clin Pract 2012; 66: 1224-1229.

20 Nishimura K, Izumi T, Tsukino M, et al. Dyspnea is a better predictor of 5-year survival than airway obstruction in patients with COPD. Chest 2002; 121: 1434-1440.

21 Abidov A, Rozanski A, Hachamovitch R, et al. Prognostic significance of dyspnea in patients referred for cardiac stress testing. N Engl J Med 2005; 353: 1889-1898.

22 Djärv T, Metcalfe C, Avery KN, et al. Prognostic value of changes in health-related quality of life scores during curative treatment for esophagogastric cancer. J Clin Oncol 2010; 28: 1666-1670.

23 Healy LA, Ryan AM, Moore J, et al. Health-related quality of life assessment at presentation may predict complications and early relapse in patients with localized cancer of the esophagus. Dis Esophagus 2008; 21: 522-528.

24 Tessier JF, Nejjari C, Letenneur L, et al. Dyspnea and 8-year mortality among elderly men and women: the PAQUID cohort study. Eur J Epidemiol 2001; 17: 223-229. 
25 Tinetti ME, McAvay G, Chang SS, et al. Effect of chronic disease-related symptoms and impairments on universal health outcomes in older adults. J Am Geriatr Soc 2011; 59: 1618-1627.

26 Baker K, Barsamian J, Leone D, et al. Routine dyspnea assessment on unit admission. Am J Nurs 2013; 113: 42-49.

27 Banzett RB, Howell MD, O’Donnell CR, et al. Dyspnea prevalence and risk of adverse event in a general hospital population. Am J Respir Crit Care Med 2013; 187: A2508.

28 Baker K, Stevens J, Anderson L, et al. Dyspnea assessed by nurses every shift - prevalence and risk prediction in a pilot study. Am J Respir Crit Care Med 2014; 189: A1787.

29 Stenton C. The MRC breathlessness scale. Occup Med (Lond) 2008; 58: 226-227.

30 Bausewein C, Booth S, Higginson IJ. Measurement of dyspnoea in the clinical rather than the research setting. Curr Opin Support Palliat Care 2008; 2: 95-99.

31 Dorman S, Byrne A, Edwards A. Which measurement scales should we use to measure breathlessness in palliative care? A systematic review. Palliat Med 2007; 21: 177-191.

32 Yorke J, Moosavi SH, Shuldham C, et al. Quantification of dyspnoea using descriptors: development and initial testing of the Dyspnoea-12. Thorax 2010; 65: 21-26.

33 Lansing RW, Gracely RH, Banzett RB. The multiple dimensions of dyspnea: review and hypotheses. Respir Physiol Neurobiol 2009; 167: 53-60.

34 Meek PM, Banzett R, Parshall MB, et al. Reliability and validity of the multidimensional dyspnea profile. Chest 2012; 141: 1546-1553. 